\title{
Using agro-industrial wastes for mixotrophic growth and lipids production by the green microalga Chlorella sorokiniana
}

\author{
Antonio León-Vaz ${ }^{\mathrm{a}}$, Rosa León ${ }^{\mathrm{a}}$, Encarnación Díaz-Santos ${ }^{\mathrm{a}}$, Javier Vigara ${ }^{\mathrm{a}}$, Sara Raposo ${ }^{\mathrm{b}}$, \\ ${ }^{a}$ Laboratory of Biochemistry, Faculty of Experimental Sciences, Marine International Campus of Excellence (CEIMAR) and CEICAMBIO, University of Huelva, 21007, Huelva, \\ Spain \\ ${ }^{\mathrm{b}}$ Center for Marine and Environmental Research - CIMA, University of Algarve - Campus de Gambelas, 8005-139 Faro, Portugal
}

\section{A R T I C LE INFO}

Article history:

Received 6 February 2018

Received in revised form 5 February 2019

Accepted 6 February 2019

Available online $\mathrm{xxx}$

\section{Keywords:}

Agro-industrial waste

Chlorella sorokiniana

fed-batch

mixotrophic

stirred tank bioreactor

wine waste lees

\begin{abstract}
A B S T R A C T
There has been growing interest in the use of microalgae for the production of biofuels, but production costs continue to be too high to compete with fossil fuel prices. One of the main limitations for photobioreactor productivity is light shielding, especially at high cell densities. The growth of the green microalga Chlorella sorokiniana, a robust industrial species, has been evaluated under different trophic conditions with traditional carbon sources, such as glucose and sucrose, and alternative low cost carbon sources, such as carob pod extract, industrial glycerol and acetate-rich oxidized wine waste lees. The mixotrophic cultivation of this microalga with wine waste lees alleviated the problems of light shielding observed in photoautotrophic cultures, improving specific growth rate $\left(0.052 \mathrm{~h}^{-1}\right)$ compared with the other organic sources. The fed-batch mixotrophic culture of Chlorella sorokiniana in a $2 \mathrm{~L}$ stirred tank reactor, with optimized nutritional conditions, $100 \mathrm{mM}$ of acetate coming from the oxidized wine waste lees and $30 \mathrm{mM}$ of ammonium, produced an algal biomass concentration of $11 \mathrm{gL}^{-1}$ with a lipid content of $38 \%(\mathrm{w} / \mathrm{w})$. This fed-batch strategy has been found to be a very effective means to enhance the biomass and neutral lipid productivity.
\end{abstract}

(C) 2019

\section{Introduction}

Microalgae are a heterogeneous group of photosynthetic microorganisms with unique properties, widely used as high nutritional value additives in aquaculture, human food, animal feed and cosmetics [1]. Per year, over 5000 tons of dry microalgal biomass are produced globally and marketed with an average value of more than 1 billion euros [2]. Microalgae are the main natural source of carotenoids $[3,4]$, a potential resource for long-chain polyunsaturated essential fatty acids [5] and, given the diversity of microalgal species that exist and the many that remain to be identified, it is estimated that they can be a potential source of new bioactive compounds still unexplored with importance in the food and pharmaceutical industries $[6,7]$. Moreover, there has been an increasing interest in microalgae for the production of carbon-neutral biofuels [ 810$]$ and for their ability to mitigate greenhouse gas emissions, which has stimulated research into the design of cheaper and more efficient photobioreactors $[11,12]$. However, the cost of microalgae production, harvesting and

Abbreviations: A. acetii, Acetobacter acetii; C. sorokiniana, Chlorella sorokiniana; DMSO, Dimethylsulfoxide; DW, Dry Weight; FI, Fluorescence Intensity; HPLC, High Performance Liquid Chromatography; ISA, Ionic Strength Adjusted; SRT, Stirred Tank

Corresponding author at: Universidade do Algarve - FCT Ed. 8, CIMA - Centre of Marine Research and Environmental, Campus de Gambelas, 8005-119 Faro, Portugal. Email address: sraposo@ualg.pt (S. Raposo) processing is still very far from being competitive with that of fossil fuels [13].

The importance of bioreactor design is more evident in high-cell density cultures [14], due to the difficulties of dealing with cellular self-shading within the photobioreactor. While the input of carbon, nitrogen or other nutrients in a reactor can be controlled by operational factors (dilution rate, initial concentration), light input is controlled by the design of the photobioreactor and the avaibility of external light, which changes through the day and the year. In addition to the standard photoautotrophic growth, many microalgal species can be cultured under heterotrophic conditions with an organic source of carbon and/or energy [15], or under mixotrophic conditions, where they are grown with an organic carbon source in the presence of light [16]. Mixotrophic growth is a mixed approach that combines aspects of both photo- and heterotrophic technologies and a promising alternative for microalgae, capitalizing on the simultaneous assimilation of carbon dioxide and organic carbon sources such as sugars [17,18], acetate [19] or glycerol [20]. However, to achieve economically feasible mixotrophic production it is necessary to choose a cheap organic carbon source. The combination of mixotrophic culture and reuse of industrial waterwastes is an interesting option to achieve reduced costs and improve the overall economics of the process by promoting the circular economy [21].

Different agro-industrial wastes have been used successfully as carbon source for yeast and microalgae [22], including carob pod extract [23], corn powder hydrolysate [24], cheese whey effluent [25], urban wastewater [26] or apple vinegar [27]. In addition, the low 
price of biodiesel has encouraged intensive research into low cost carbon sources and optimal conditions for oil accumulation, together with the production of high added-value co-products, in a sustainable biorefinery approach [28].

In the present work, the growth of the green microalga Chlorella sorokiniana (C. sorokiniana), a robust industrial species, tolerant to high temperatures and levels of solar irradiance [40], has been evaluated under different trophic conditions with traditional carbon sources, such as glucose and sucrose, and alternative low cost carbon sources, such as carob pod extract, industrial glycerol and acetate-rich oxidized wine waste lees (oxidized wine waste lees). The best carbon source was found to be the oxidized wine waste lees, which has been chosen to study $\mathrm{C}, \mathrm{N}$ and light limitations and to establish a fed-batch system where the highest values of biomass and neutral lipids were obtained.

\section{Materials and methods}

\section{Algal strain and standard culture conditions}

C. sorokiniana 211-32 was obtained from the culture collection of the Institute of Plant Biochemistry and Photosynthesis, IBVF, (Seville, Spain) and grown at $25^{\circ} \mathrm{C}$ and aerated with $3 \% \mathrm{CO}_{2}$-enriched air in liquid Sueoka medium [30] containing $\left(\mathrm{g} \mathrm{L}^{-1}\right) 0.72$ $\mathrm{KH}_{2} \mathrm{PO}_{4}, 1.44 \mathrm{~K}_{2} \mathrm{HPO}_{4}, 0.02 \mathrm{MgSO}_{4} \cdot 7 \mathrm{H}_{2} \mathrm{O}, 0.01 \mathrm{CaCl}_{2} \cdot 2 \mathrm{H}_{2} \mathrm{O}, 0.50$ $\mathrm{NH}_{4} \mathrm{Cl}$ and $5 \mathrm{~mL} \mathrm{~L}^{-1}$ of traces solution containing $\left(\mathrm{g} \mathrm{L}^{-1}\right) 10.0$ EDTA, $2.28 \mathrm{H}_{3} \mathrm{BO}_{3}, 4.40 \mathrm{ZnSO}_{4} \cdot 7 \mathrm{H}_{2} \mathrm{O}, 1.02 \mathrm{MnCl}_{2} \cdot 4 \mathrm{H}_{2} \mathrm{O}, 1.00 \mathrm{FeSO}_{4} \cdot 7 \mathrm{H}_{2} \mathrm{O}$, $0.32 \mathrm{CoCl}_{2} \cdot 6 \mathrm{H}_{2} \mathrm{O}, 0.32 \mathrm{CuSO}_{4} \cdot 5 \mathrm{H}_{2} \mathrm{O}$ and $0.22 \mathrm{Mo}_{7} \mathrm{O}_{24}\left(\mathrm{NH}_{4}\right)_{6} \cdot 4 \mathrm{H}_{2} \mathrm{O}$. For mixotrophic growth, the medium was supplemented with the organic carbon source indicated in each experiment in place of $\mathrm{CO}_{2}$-enriched air and the cultures were agitated at $100 \mathrm{rpm}$. Pre-inocula were incubated for 3 days before the experiments and inoculated to obtain an initial concentration of $0.1 \mathrm{~g} \mathrm{~L}^{-1}$ of dry weight.

All cultures were grown under continuous white light irradiation of $100 \mathrm{E} \mathrm{m}^{-2} \mathrm{~s}^{-1}$. For high irradiance experiments light was provided with halogen adjustable lamps and intensity measured by a Delta OHM quantum photo radiometer HD 9021 equipped with a LP 9021 PAR sensor (Delta OHM, Italy). Carob pod extract is a sugar-rich extract by-product from the Portuguese processing carob industry, as described [31], with (w/w) $56 \%$ sucrose, $26 \%$ glucose and $18 \%$ fructose. Industrial glycerol was obtained from BioVegetal SA Company and the wine waste lees were kindly provided by the Wine Cooperative Ntra Sra de la Estrella Chucena (Huelva, Spain).

Wine waste lees were converted to vinegar by oxidative incubation with Acetobacter acetii (A. acetii) at $28^{\circ} \mathrm{C}$ and $200 \mathrm{rpm}$. A. acetii was cultured in $50 \mathrm{~mL}$ YPD medium $\left(20 \mathrm{~g} \mathrm{~L}^{-1}\right.$ peptone, $10 \mathrm{~g} \mathrm{~L}^{-1}$ yeast extract and $20 \mathrm{~g} \mathrm{~L}^{-1}$ mannitol). After $48 \mathrm{~h}, A$. acetii was collected by centrifugation at $4500 \mathrm{rpm}$ for $5 \mathrm{~min}$ and resuspended in $250 \mathrm{~mL}$ filtered and autoclaved wine waste lees. The bacteria were cultured at $28^{\circ} \mathrm{C}$ and $300 \mathrm{rpm}$ agitation until a final acetate concentration of $3-5 \%(v / v)$ and no significant quantities of ethanol. Finally, they were harvested by centrifugation at $4500 \mathrm{rpm}$ for $20 \mathrm{~min}$ and the supernatant used as carbon source. Composition of the oxidized wine waste lees was determined using an ion chromatograph Metrhrom IC plus88, equipped with a conductivity detector with chemical cation suppressor and a Metrosep A Supp 5 - $205 / 40$ " column. The mobile phase was $\mathrm{NaHCO}_{3}(1.404 \mathrm{mM}) / \mathrm{Na}_{2} \mathrm{CO}_{3}(3.368 \mathrm{mM})$, at a flow rate of $0.7 \mathrm{~mL} \mathrm{~min}^{-1}$. The main anions in the oxidized wine waste lees were: Acetate $\left(5.0 \mathrm{~g} \mathrm{~L}^{-1}\right), \mathrm{NO}_{2}-\left(5.9 \mathrm{mg} \mathrm{L}^{-1}\right), \mathrm{NO}_{3^{-}}\left(20.7 \mathrm{mg} \mathrm{L}^{-1}\right)$, $\mathrm{Cl}-\left(56.8 \mathrm{mg} \mathrm{L}^{-1}\right), \mathrm{Br}-\left(25.4 \mathrm{mg} \mathrm{L}^{-1}\right), \mathrm{SO}_{4}{ }^{2-}\left(606.4 \mathrm{mg} \mathrm{L}^{-1}\right)$, and $\mathrm{PO}_{4}{ }^{3-}$
$(<\mathrm{LD})$. For mixotrophic cultures, $120 \mathrm{~mL} \mathrm{~L}^{-1}$ of oxidized wine waste lees were added.

\section{Fed-batch culture}

For the fed-batch culture, C. sorokiniana was grown for $3 \mathrm{~d}$ in a $500 \mathrm{~mL}$ Erlenmeyer flask with $250 \mathrm{~mL}$ Sueoka medium supplemented with $100 \mathrm{mM}$ acetic acid, in the form of oxidized wine waste lees, and $30 \mathrm{mM}$ ammonium chloride, at $25^{\circ} \mathrm{C}$ and agitation at $150 \mathrm{rpm}$. $10 \%(\mathrm{v} / \mathrm{v})$ of the culture was then transferred to a $2 \mathrm{~L}$-stirred tank (STR) jacketed vessel (Applikon Biotechnology, England), equipped with a Rushton-type turbine (radial flow) and a microporous sparger for the aeration, connected to a controller (Bio Controller ADI 1030, Apllikon, Holland). The dissolved $\mathrm{O}_{2}$, temperature and $\mathrm{pH}$ were measured with specific probes, polarographic $\mathrm{DO}_{2}$ sensor, Pt-100 sensor in thermowell in top plate and classic $\mathrm{pH}$ sensor respectively, and the values were frequently registered. The temperature of the reactor was maintained at $30 \pm 2{ }^{\circ} \mathrm{C}, \mathrm{pH}$ between 6.5 and 7 , and the agitation at $550 \mathrm{rpm}$. The culture was continuously mixed with air at a flow rate of $0.75 \mathrm{vvm}$ and the light intensity was $100 \mathrm{E} \mathrm{m}^{-2} \mathrm{~s}^{-1}$. During the fed-batch experiment, carbon and nitrogen sources were added to the reactor at 72,144, 216 and $288 \mathrm{~h}$ culture, such that the concentration in the vessel did reach $100 \mathrm{mM}$ of acetic acid and between 20 and $30 \mathrm{mM}$ of ammonium chloride after each addition. The volume of the additions was $200 \mathrm{~mL}$ of medium, and a sample was collected before and after each addition. The routine samples were taken every $24 \mathrm{~h}$.

\section{Analytical determinations}

For dry weight (DW) determination, a $5 \mathrm{~mL}$ sample of culture was filtered through pre-tared Whatman GF/F Filter paper (Whatman International Ltd, Maidstone, UK), the filters were oven-dried overnight at $100{ }^{\circ} \mathrm{C}$, cooled in a desiccator and weighed on an analytical balance. DW was obtained as the difference between initial and final weight. All measurements were made in triplicate.

Neutral lipid content was quantified by fluorescence spectrometry, using Nile Red, as described [32] and optimized [33] for this microalga. Fluorescence was measured at an excitation wavelength of $510 \mathrm{~nm}$ and an emission wavelength ranging between 500 and $800 \mathrm{~nm}$ A $200 \mu \mathrm{L}$ aliquot of C. sorokiniana cell suspension, $1800 \mu \mathrm{L}$ of PBS buffer and $100 \mu \mathrm{L}$ of DMSO (Dimethylsulfoxide) were added to the fluorescence cuvette and the spectrum was recorded after 20 minutes of stirring at $40^{\circ} \mathrm{C}$. Thereafter, $10 \mu \mathrm{L}$ of Nile Red solution ( $0.1 \mathrm{mg}$ of Nile Red in $1 \mathrm{~mL}$ acetone) were added and the spectrum recorded again after $15 \mathrm{~min}$ stirring at $40^{\circ} \mathrm{C}$. The fluorescence value corresponds to the difference spectrum with and without dye and the results expressed in fluorescence intensity (FI). A calibration curve was performed using triolein, representing the fluorescence intensity versus the triolein concentration (Equation 1). This standard curve was performed according to [34]:

Fluorescence intensity $(\mathrm{FI})=3645.8 \times$ Triolein concentration $(\mathrm{g}$ $L^{-1}$ ) Equation 1

Acetate was determined using a high-performance liquid chromatography (Hitachi LaChrom Elite HPLC, Japan) equipped with a refractive index detector (Hitachi L-2490, Japan). A Sugar-Pak column (Waters) was used with Milli-Q water as eluent at $83^{\circ} \mathrm{C}$ and flow rate of $0.5 \mathrm{~mL} \mathrm{~min}^{-1}$.

Ammonium in the culture medium was determined with an ammonium ion selective electrode (Crison Instruments S. A. Spain). The total ionic strength was adjusted with Ionic Strength Adjusted (ISA) buffer solution $\left(1 \mathrm{M} \mathrm{MgSO}_{4}\right)$. For each measurement, $1 \mathrm{~mL}$ of sample 
was mixed with $1 \mathrm{~mL}$ ISA solution and $8 \mathrm{~mL}$ of deionized water at $25^{\circ} \mathrm{C}$.

All tests were carried out in triplicate and the results were the means of 6 values ( 3 replicates of the process and 2 replicates of the analysis).

\section{Determination of culture efficiency and kinetic parameters}

Specific growth rates $\left(\mathrm{h}^{-1}\right)$ were calculated in exponential phase of growth, as the slope fitted by linear regression of the $\ln (\mathrm{DW})$ as a function of time, using the DMFIT modeling tool (http://modelling. combase.cc).

Doubling time $\left(\mathrm{t}_{\mathrm{D}}\right)$ was calculated according to:

$$
t_{D}(h)=\frac{\ln 2}{\mu}
$$

where $\left(h^{-1}\right)$ is the specific growth rate calculated as described above. The lipid content was calculated according to:

$$
\mathrm{Y}_{\mathrm{L} / \mathrm{X}}=\frac{\mathrm{L}_{\mathrm{i}}-\mathrm{L}_{0}}{\mathrm{X}_{\mathrm{i}}-\mathrm{X}_{0}}
$$

where $\mathrm{X}_{\mathrm{i}}$ and $\mathrm{L}_{\mathrm{i}}$ are the dry cell weight and lipid concentration on day $t_{i}$, respectively, and $X_{0}$ and $L_{0}$ are the dry cell weight and lipid concentration on day $\mathrm{t}_{0}$ (first day), respectively.

The lipid yield was calculated according to:

$$
Y_{L / S}=\frac{L_{i}-L_{0}}{S_{0}-S_{i}}
$$

where $S_{i}$ and $S_{0}$ are the acetate concentration on day $t_{i}$ and $t_{0}$, respectively and $\mathrm{L}_{\mathrm{i}}$ and $\mathrm{L}_{0}$ are the lipid concentration on day $\mathrm{t}_{\mathrm{i}}$ and day $\mathrm{t}_{0}$, respectively.

Biomass productivity $\left(\mathrm{P}_{\text {biom }}\right)$ was calculated as the slope, fitted by linear regression, of the biomass produced (dry weight) as a function of time.
Lipid productivity $\left(\mathrm{P}_{\text {lipid }}\right)$ was calculated by:

$$
P_{\text {lipid }}\left(g L^{-1} d a y^{-1}\right)=\frac{L_{\max }}{t_{i}}
$$

where $\mathrm{L}_{\max }$ is the maximum lipid concentration on day $t_{\mathrm{i}}$.

\section{Results and discussion}

Comparison of the influence of the effective light on the growth of $C$. sorokiniana microalga, cultivated under different trophic conditions

The dependence of productivityof photoautotrophically grown microalgal cultures on the availability of light is well known. If no other nutrient is limiting and all operational parameters are optimal, specific growth rate depends on light intensity up to a maximum saturating value $[35,36]$. Due to the shading effects of cells upon one another, the design of photobioreactors is especially important to ensure adequate light distribution, one of the most difficult parameters to handle when scaling up photobioreactors [37] because it depends not only on external irradiance, but also on the diameter of the reactor and the cell density of the cultures. The effect of self-shading on the effective light in C. sorokiniana cultures was evaluated and compared with the influence of effective light on photo- and mixotrophically grown cultures of this microalga.

To evaluate the effect of cellular self-shading on the effective light in different points of a photobioreactor, cultures of $C$. sorokiniana were prepared with cell densities ranging between 0.1 to $2 \mathrm{~g} \mathrm{~L}^{-1} \mathrm{DW}$ and two different experiments were performed. For one, the cultures were exposed to an external irradiance of $850 \mu \mathrm{E} \mathrm{m}^{-2} \mathrm{~s}^{-1}$ and the effective light was measured at different distances from the surface of the reactor (Fig. 1A). For the other, the cultures were exposed to increasing irradiance, with values ranging from 200 to $1200 \mu \mathrm{E} \mathrm{m}^{-2} \mathrm{~s}^{-1}$ at the surface of the bioreactor, and the effective light was measured at $3.5 \mathrm{~cm}$ from the surface of the bioreactor (Fig. 1B).

As shown in Fig. 1A, for a cell density of $1 \mathrm{~g} \mathrm{~L}^{-1}$, at $2 \mathrm{~cm}$ from the surface, the effective light was reduced by about $90 \%$. Increasing light intensity at the surface of the reactor caused an increase in effective local light (Fig. 1B), but for high density cultures the effective light measured at only a few centimeters from the surface continued to be extremely low. For cultures with cell densities of $1 \mathrm{~g} \mathrm{~L}^{-1}$, increasing light on the surface to $1200 \mu \mathrm{E} \mathrm{m}^{-2} \mathrm{~s}^{-1}$ provided a local effective light of only $60 \mu \mathrm{E} \mathrm{m}^{-2} \mathrm{~s}^{-1}$ at $3.5 \mathrm{~cm}$ from the reactor surface. The light intensity reached was only $11 \mu \mathrm{E} \mathrm{m}^{-2} \mathrm{~s}^{-1}$ for cultures with cell densities of $2 \mathrm{~g} \mathrm{~L}^{-1} \mathrm{DW}$ under the same conditions. This means that $>99 \%$ of the light applied at the surface of the reactor was ab-

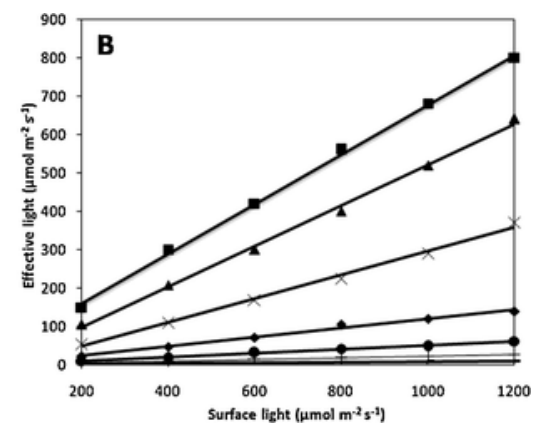

Fig. 1. Influence of cell density on cellular self-shading in C. sorokiniana cultures. The light intensity was measured at different distances from the surface for a fixed surface light of $850 \mu \mathrm{E} \mathrm{m}^{-2} \mathrm{~s}^{-1}$ (A) and for different light intensities at the reactor surface at a fixed distance of $3.5 \mathrm{~cm}$ from the surface (B). In both cases C. sorokiniana cultures of 0.1 ( ), 0.2 ( ), $0.3(\mathrm{x}), 0.7(\mathrm{)}), 1(+), 1.3(-)$ and $2 \mathrm{~g} \mathrm{~L}^{-1}()$ of dry weight were used. 
sorbed across the bioreactor due to the shading effect for this cell density.

Difficulties in obtaining high-density cultures due to self-shading have been extensively studied for different photoautotrophically grown microalgae $[38,39]$. Although efficient agitation can guarantee that all the cells will be temporarily near the surface receiving maximum irradiance, this is not sufficient to compensate for the shelf-shading effect and light gradients within the reactor. Moreover, it is necessary to remember that over certain values, an excess of light is inhibitory [40], so that increasing light on the surface is not the solution to overcoming self-shading in high cell-density photoautrophic cultures.

Since the growth of microalgae in mixotrophic conditions is less dependent on photosynthesis than growth in phototropic conditions, it is expected that the productivity of a mixotrophic culture is not as strongly influenced by the availability of light as is that of a phototrophycally grown culture. In order to check this possibility, $C$. sorokiniana was cultured both in photoautotrophic $\left(\mathrm{CO}_{2}+\right.$ light $)$ and mixotrophic (acetic acid + light) conditions in cylindrical bottles of $1.25,2.5,5$ and $9 \mathrm{~cm}$ radius with an initial cellular concentration of $0.1 \mathrm{~g} \mathrm{~L}^{-1}$. The specific growth rate and doubling time were calculated in the middle of the exponential phase as indicated in Materials and Methods (Fig. 2; Table 1).

As expected, productivity of the cultures decreased in inverse proportion to the radius of the reactor and, interestingly, the reduction of growth rate was much less acute in the case of mixotrophic cultures. When plotting the doubling time against the radius of the Erlenmeyer, a slope of $1.12 \mathrm{~h} \mathrm{~cm}^{-1}$ was obtained for mixotrophic cultures, while the slope reached $2.40 \mathrm{~h} \mathrm{~cm}^{-1}$ for photoautotrophic growth cultures.

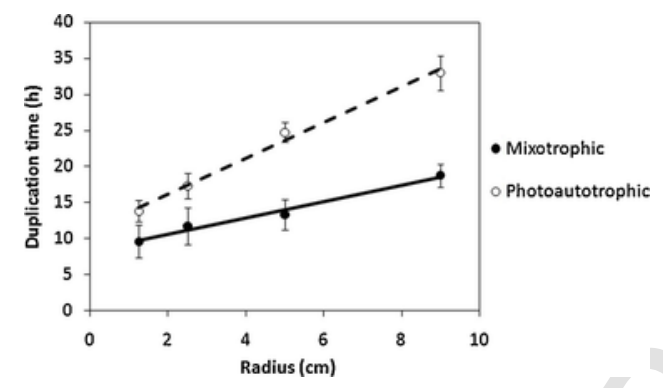

Fig. 2. Influence of recipient diameter on doubling time. Measurements with different mixotrophic (continuous line) and photoautotrophic (dash line) cultures of $C$. sorokiniana, with a light of $100 \mu \mathrm{E} \mathrm{m}^{-2} \mathrm{~s}^{-1}$ and an agitation of $100 \mathrm{rpm}$. The doubling time of the cultures was calculated as described in Materials and Methods. The carbon concentration was $16 \mathrm{mM}$ acetate in mixotrophic and a similar concentration of $\mathrm{CO}_{2}$ in photoautotrophic.

\section{Table 1}

Maximum biomass produced and specific growth rate for the $C$. sorokiniana microalgae, cultivated in different trophic conditions.

\begin{tabular}{llll}
\hline & $\begin{array}{l}\text { Radius of the bioreactor } \\
(\mathrm{cm})\end{array}$ & $\begin{array}{l}\text { Maximum biomass } \\
\left(\mathrm{h}^{-1}\right)\end{array}$ & \begin{tabular}{l}
$\left(\mathrm{g} \mathrm{L}^{-1}\right)$ \\
\hline Mixotrophic
\end{tabular} \\
& 1.25 & 0.072 & 1.32 \\
& 2.50 & 0.059 & 1.47 \\
Photoautotrophic & 5.00 & 0.052 & 1.28 \\
& 9.00 & 0.037 & 1.08 \\
& 1.25 & 0.050 & 1.16 \\
Heterotrophic & 2.50 & 0.040 & 1.18 \\
& 5.00 & 0.028 & 0.66 \\
& 9.00 & 0.021 & 0.39 \\
\end{tabular}

The value of was determined in exponential phase of the cultures and maximum biomass was determined at $48 \mathrm{~h}$ of culture. - Specific growth rate.
The slope for mixotrophic cultures was less than half that observed in photoautotrophic conditions.

It is also interesting to note that mixotrophic growth was, in all cases, higher than photoautotrophic, and both the specific growth rate and the final biomass reached higher values in the mixotrophic cultures. These values have been summarized in Table 1, which also includes data for heterotrophic cultures tested under the same conditions as the mixotrophic, except for light. The growth rate of mixotrophic cultures was more than twice as high as that of photoautotrophic (Fig. 2; Table 1), and was also higher than the growth rate of heterotrophic cultures (Table 1). The differences between photoautotrophic and mixotrophic cultures were more pronounced when the radius of the vessel was larger, confirming that the light-dependence was lower in the case of mixotrophic growth, which combines advantages of photoautotrophic and heterotrophic cultures. In mixotrophic cultures, both the external organic carbon source and the endogenously generated $\mathrm{CO}_{2}$ are metabolized, contributing to an important increase in productivity and to a lower dependence on external light.

Similar results have been reported comparing mixo- and photoautotrophic growth in other species of the genus Chlorella, such as $C$. vulgaris [41] or $C$. protothecoides [42]. There are also previous reports comparing the growth of $C$. sorokiniana under photoautotrophic and mixotrophic conditions, with organic carbon sources such as glucose [43] or acetate [44]. All these studies concluded that $\mu_{\max }$ in mixotrophic cultures was much higher than for photosynthetic conditions, in agreement with our data for acetate-based mixotrophic cultures. Furthermore, others [43] determined the inorganic carbon concentration in different trophic conditions and observed that the inorganic carbon dissolved in the culture medium decreased in photoautotrophic, increased in heterotrophic and remained approximately constant in mixotrophic cultures. This indicates that the $\mathrm{CO}_{2}$ released due to respiration was photosynthetically assimilated by $C$. sorokiniana.

\section{Different carbon sources for C. sorokiniana}

The choice of an adequate carbon source is essential for optimal mixotrophic growth of microalgae. To evaluate the carbon source preferences of $C$. sorokiniana in terms of biomass productivity, it was grown in Sueoka medium supplemented with different organic carbon sources, at an initial concentration of $20 \mathrm{~g} \mathrm{~L}^{-1}$ (Fig. 3). The carbon sources tested were glucose, sucrose, industrial glycerol, oxidized wine waste lees and carob pod extract [31]. A control grown in

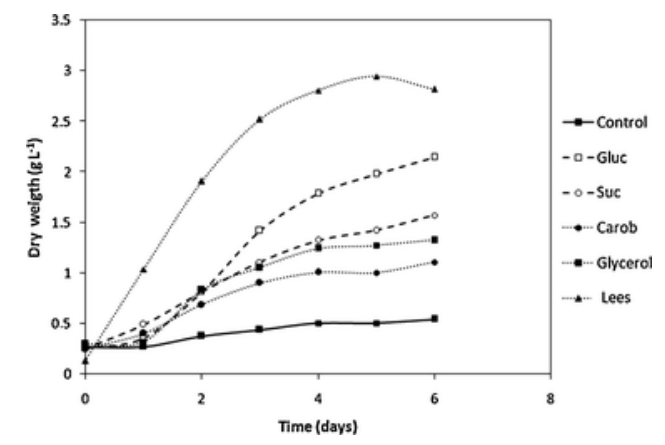

Fig. 3. Growth curve of $C$. sorokiniana cultivated with different carbon sources. All cultures were grown at $25^{\circ} \mathrm{C}, 100 \mathrm{rpm}$ and a light intensity of $100 \mu \mathrm{E} \mathrm{m}^{-2} \mathrm{~s}^{-1}$, with $20 \mathrm{~g}$ $\mathrm{L}^{-1}$ of the indicated carbon source. A control without carbon source (continuous line) is included. The carbon sources tested were different sugars (dashed line) such as glucose (Gluc) or sucrose (Suc); or different types of wastes (point line) such as carob pod extract (Carob), industrial glycerol (Glycerol) or oxidized wine waste lees (Lees). 
the same conditions without any carbon source was also included. All cultures were carried out in $250 \mathrm{~mL}$ Erlenmeyer flasks ( $4 \mathrm{~cm}$ radius), as described in Materials and Methods.

As Fig. 3 shows, C. sorokiniana can actively use glucose, sucrose, glycerol and acetate as carbon sources. Processed wine waste lees was non toxic to $C$. sorokiniana, but also provided higher growth rate than equivalent concentrations of acetate (data not shown) and was the best organic carbon source. Growth with carob pod extract was higher than in control conditions, but slightly lower than with sucrose, glucose or industrial glycerol (Table 1). This was an expected result because both glucose and sucrose concentrations are lower in carob pod extract (26 $\%$ and $56 \%$, w/w, respectively) than in the trials with the respective single sugar. Besides, in agreement with other studies [4], in the presence of a substrate with more than one sugar, as is the case, the microalgae assimilate the sugar with higher affinity.

Processed wine waste lees was chosen as organic carbon source for mixotrophic growth of $C$. sorokiniana because it provided the highest growth rate, with a $\mu$ value of $0.036 \mathrm{~h}^{-1}$, about 7 -fold higher than the specific growth rate of the control culture with no carbon source (Table 2). The oxidized wine waste lees can be an optimal source of acetate for the mixotrophic growth of $C$. sorokiniana and other microalgae with multiple advantages, such as lower cost and less susceptibility to contamination than other widely used carbon sources. Besides wine lees, other industrial wastes could be explored as a source of acetate. Wastes from textile industries or the effluent of anaerobic digesters may be promising alternatives [25].

\section{Optimization of initial acetate and ammonium concentrations for $C$. sorokiniana cultures}

C. sorokiniana was cultured with increasing concentrations of oxidized wine waste lees, adjusted to provide acetate concentrations ranging from 16 to $100 \mathrm{mM}$ (Fig. 4). Samples were periodically withdrawn to determine DW and acetate concentration in the culture medium. No inhibitory effect of the lees was observed up to concentrations equivalent to $300 \mathrm{mM}$ acetate (data not shown). Increasing

\section{Table 2}

Specific growth rate for $C$. sorokiniana cultivated with different carbon sources. The cultures were grown at $25^{\circ} \mathrm{C}, 100 \mathrm{rpm}$ and a light intensity of $100 \mu \mathrm{E} \mathrm{m}^{-2} \mathrm{~s}^{-1}$, with $20 \mathrm{~g}$ $\mathrm{L}^{-1}$ of the indicated carbon source.

\begin{tabular}{ccccccc}
\hline & CONT - & Gluc & Suc & Carob & Glycerol & Lees \\
\hline$\left(\mathrm{h}^{-1}\right)$ & 0.005 & 0.027 & 0.016 & 0.011 & 0.016 & 0.036 \\
\hline
\end{tabular}

A control without carbon source (Cont-) has been also included. The carbon sources tested were glucose (Gluc), sucrose (Suc), carob pod extract (Carob), industrial glycerol (Glycerol) and oxidized wine waste lees (Lees). oxidized wine waste lees concentration caused an increase in the final biomass obtained up to acetate concentrations of about $80 \mathrm{mM}$, although growth was saturated for higher acetate concentrations (Fig. $4 \mathrm{~A})$.

Acetate in the culture medium was only completely exhausted in cultures with an initial concentration of $16 \mathrm{mM}$. Strong acetate consumption was observed in the first $72 \mathrm{~h}$ of culture (Fig. 4B), as deduced from the initial slope of consumption kinetics, which increased slightly with initial acetate concentration of acetate, from 0.315 to $0.544 \mathrm{mM} \mathrm{h}^{-1}$. However, after $72 \mathrm{~h}$, acetate assimilation practically stopped although it was still available in the medium (Fig. 4B).

The drastic reduction in growth observed in Fig. 4B indicated that another limiting nutrient existed in these conditions. The high content of phosphate in the Sueoka medium and the considerable content of sulphate in the oxidized wine lees, pointed to nitrogen as the most likely limiting nutrient. To check this, $C$. sorokiniana cultures with an initial acetate concentration of $100 \mathrm{mM}$ were incubated with different ammonium concentrations, ranging from 8 to $100 \mathrm{mM}$ (Fig. 5). The highest dry weight was observed with initial ammonium concentrations between $20 \mathrm{mM}$ and $30 \mathrm{mM}$. For $50 \mathrm{mM}$ or higher, there was an important growth inhibition (Fig. 5A), as previously described for other microalgae [45]. After $48 \mathrm{~h}$, ammonium was practically exhausted for initial ammonium concentrations below $30 \mathrm{mM}$.

Increasing ammonium concentration allowed higher biomass densities, which increased from $2.8 \mathrm{~g} \mathrm{~L}^{-1} \mathrm{DW}$ in $4 \mathrm{~d}$, with $8 \mathrm{mM}$, to almost $4 \mathrm{~g} \mathrm{~L}^{-1} \mathrm{DW}$ in the same time with $20 \mathrm{mM}$ (Fig. 5A). Increasing ammonium concentration represented a 3 -fold increase in biomass obtained in mixotrophic Control medium $(16 \mathrm{mM}$ acetate and $8 \mathrm{mM}$ ammonium), which is about $1.5 \mathrm{~g} \mathrm{~L}^{-1}$ of DW (Fig. 4B). Due to these results, further experiments were performed with initial concentrations of $100 \mathrm{mM}$ acetate, supplied with oxidized wine waste lees, and $30 \mathrm{mM}$ ammonium chloride.

\section{Influence of acetate concentration on neutral lipids productivity}

To investigate the influence of acetate concentration on accumulation of neutral lipids, mid log phase C. sorokiniana cultures were transferred to nitrogen- deprived culture medium, with oxidized wine waste lees, adjusted to provide initial acetate concentrations of 16, 50 and $100 \mathrm{mM}$. Samples were collected every $24 \mathrm{~h}$ after nitrogen deprivation to determine the content of neutral lipids, using Nile red staining (Fig. 6). This experiment has confirmation that there is an important accumulation of neutral lipids under $-\mathrm{N}$ deprivation, both expressed as lipid concentration (Fig. 6A) and as percentage of dry weight (Fig. 6B), as has been previously described in C. sorokiniana and other microalgae $[17,46]$.
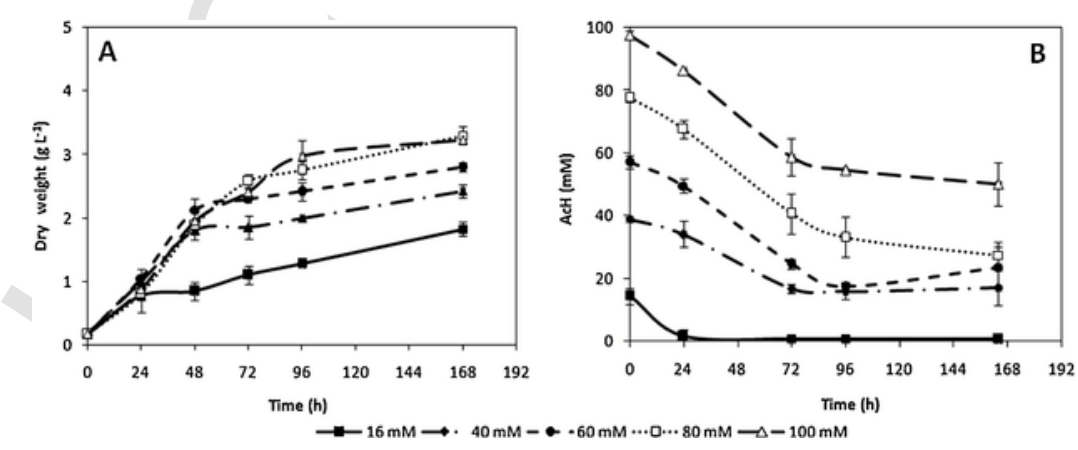

Fig. 4. Growth curve (A) and acetate consumption (B) for C. sorokiniana cultivated in mixotrophic conditions with increasing concentrations of acetate. Cultures were grown at $25^{\circ} \mathrm{C}, 100 \mathrm{rpm}$ and a light intensity of $100 \mu \mathrm{E} \mathrm{m}^{-2} \mathrm{~s}^{-1}$, in standard medium with $8 \mathrm{mM}$ ammonium and increasing additions of wine waste lees, to provide acetate concentrations between $16-100 \mathrm{mM}$. Initial $\mathrm{pH}$ was adjusted to $6.5-7$ in all cultures. 

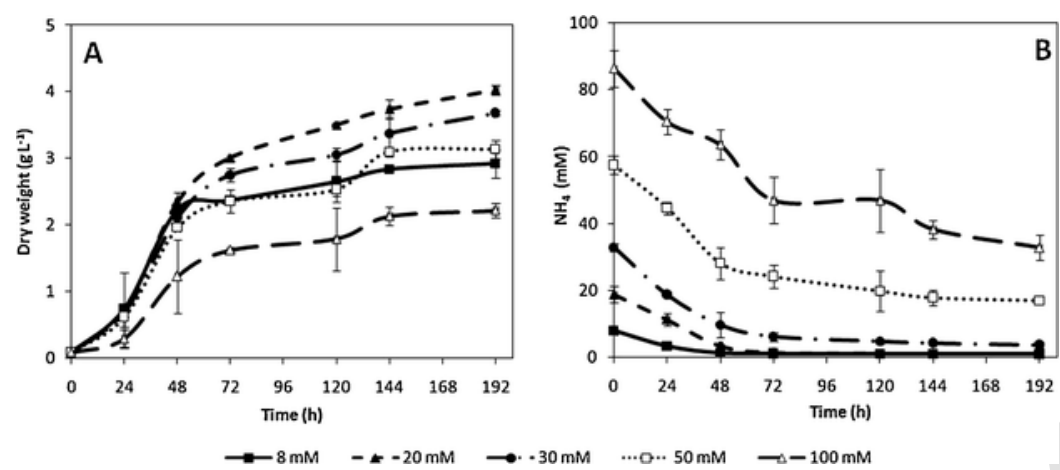

Fig. 5. Growth curve (A) and ammonium consumption (B) for C. sorokiniana cultivated in mixotrophic conditions with increasing concentrations of ammonium. Cultures were grown at $25^{\circ} \mathrm{C}, 100 \mathrm{rpm}$ and a light intensity of $100 \mu \mathrm{E} \mathrm{m}^{-2} \mathrm{~s}^{-1}$, in mixotrophic medium with $100 \mathrm{mM}$ of acetate of wine waste lees and increasing ammonium concentrations ranged between $8-100 \mathrm{mM}$.
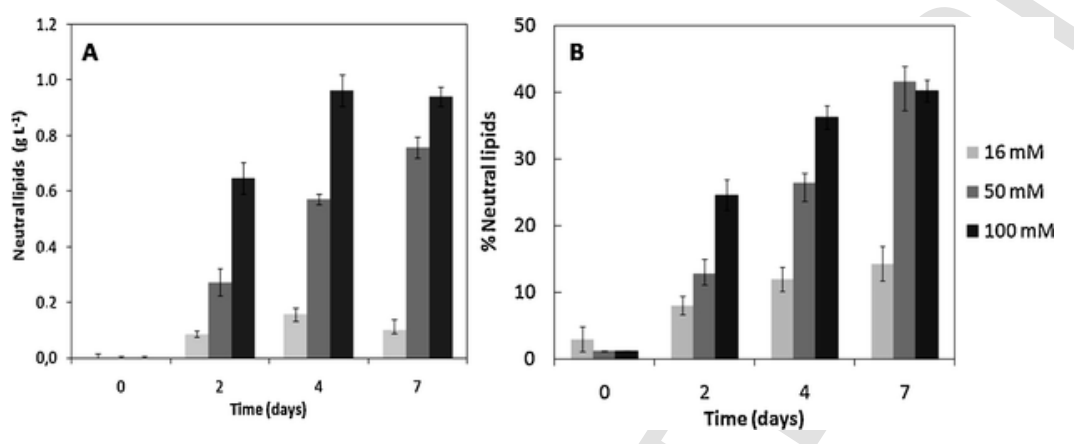

Fig. 6. Concentration of neutral lipids (A) and percentage of lipids in the dry weight (B) cultivated with $\mathrm{N}$ starvation and with different concentrations of acetate. Cultures were grown at $25^{\circ} \mathrm{C}, 100 \mathrm{rpm}$ and a light intensity of $100 \mu \mathrm{E} \mathrm{m}^{-2} \mathrm{~s}^{-1}$, in standard medium with the concentrations of 16,50 and $100 \mathrm{mM}$ of acetate. Neutral lipids were quantified as in Materials and Methods.

Moreover, increasing acetate concentration to $100 \mathrm{mM}$ allowed $C$. sorokiniana to reach neutral lipids values of $0.94 \mathrm{~g} \mathrm{~L}^{-1}$ and over $40 \%$ of dry weight, 6-times the concentration values and 3-times the percentage reached at $16 \mathrm{mM}$ acetate. These results, together with the increase of biomass observed for high acetate concentrations (Fig. 4) indicate that mixotrophically grown $C$. sorokiniana cultures with oxidized wine waste lees as carbon source can provide high neutral lipids content of $0.39 \mathrm{~g} \mathrm{~g}^{-1}$.

These observations are in agreement with recent reported studies on the effect of other carbon sources, such as glucose [47], inorganic carbonates [39] or glycerol [20] on lipid productivity in C. sorokiniana. It was also found [18] that acetate acted as an elicitor for lipid enrichment in C. sorokiniana, cultured with glucose as $\mathrm{C}$ source.

\section{Fed-batch strategy on biomass and neutral lipids productivity}

The fed-batch culture of $C$. sorokiniana was carried out in a 2 L-STR reactor, as described in Materials and Methods. Two phases were differentiated: firstly, a three-batch period for biomass production, with periodic additions of oxidized wine waste lees and ammonium chloride as detailed in Materials and Methods section $(0-72 \mathrm{~h}$, $72144 \mathrm{~h}$ and $144216 \mathrm{~h}$ ); followed by a period to induce lipid production (216 $288 \mathrm{~h}, 288 \quad 360 \mathrm{~h})$ during which the fresh medium added only contained the wine waste lees. Produced biomass and specific growth rate were determined for each fed-batch stage (Table 3). Comparing these values with those of Tables 1 and 2, it can be concluded that the biomass produced in mixotrophic STR was significantly higher than that obtained in Erlenmeyer flasks cultivated under mixotrophic, heterotrophic or photoautotrophic conditions.
Table 3

Maximum biomass produced and specific growth rates in fed-batch STR culture.

\begin{tabular}{lllllll}
\hline Time $(\mathrm{h})$ & $\begin{array}{l}0- \\
360\end{array}$ & $0-72$ & $\begin{array}{l}72- \\
144\end{array}$ & $\begin{array}{l}144- \\
216\end{array}$ & $\begin{array}{l}216- \\
288\end{array}$ & $\begin{array}{l}288- \\
360\end{array}$ \\
\hline$\left(\mathrm{h}^{-1}\right)$ & 0.039 & 0.055 & 0.011 & 0.005 & 0.004 & 0.002 \\
$\mathrm{X}\left(\mathrm{g} \mathrm{L}^{-1}\right)$ & 10.75 & 4.20 & 2.83 & 3.00 & 2.60 & 1.35 \\
\hline
\end{tabular}

- Specific Growth rate; X Maximum biomass produced in fed-batch, calculated as the difference between the maximum and the initial biomass in each phase.

The specific growth rate obtained in the STR during the first $72 \mathrm{~h}$ cultivation $\left(0.055 \mathrm{~h}^{-1}\right)$ was slightly higher $\left(0.052 \mathrm{~h}^{-1}\right)$ than that observed in Erlenmeyer flasks with an equivalent diameter, as shown in Table 1. Higher agitation speed and more efficient mode of agitation provided by the STR may be the cause of the higher growth rate. In this first fed-stage there was a high consumption of acetate and complete depletion of the nitrogen source. The growth rate and the values of acetate and ammonium consumption decreased progressively in each cycle over culture time (Fig. 7A, Table 3). The average specific growth rate observed in the photobioreactor during the whole process was $0.039 \mathrm{~h}^{-1}$. However, the total biomass produced in the 2 L-STR was approximately 10 -fold higher than that produced in Erlenmeyer flasks, increasing from $1.28 \mathrm{~g} \mathrm{~L}^{-1}$ in the flask to $11.00 \mathrm{~g} \mathrm{~L}^{-1}$ in the STR, with an equivalent radius of $5 \mathrm{~cm}$. The C:N:P ratio determined for this culture was 33:12:1, considering only the $\mathrm{C}$ supplied as acetate. Although the acetate concentration provided by the oxidized wine waste lees was lower than recommended in theoretical nutrient ratios, such as the Redfield ratio [48], which states that a CNP ratio 

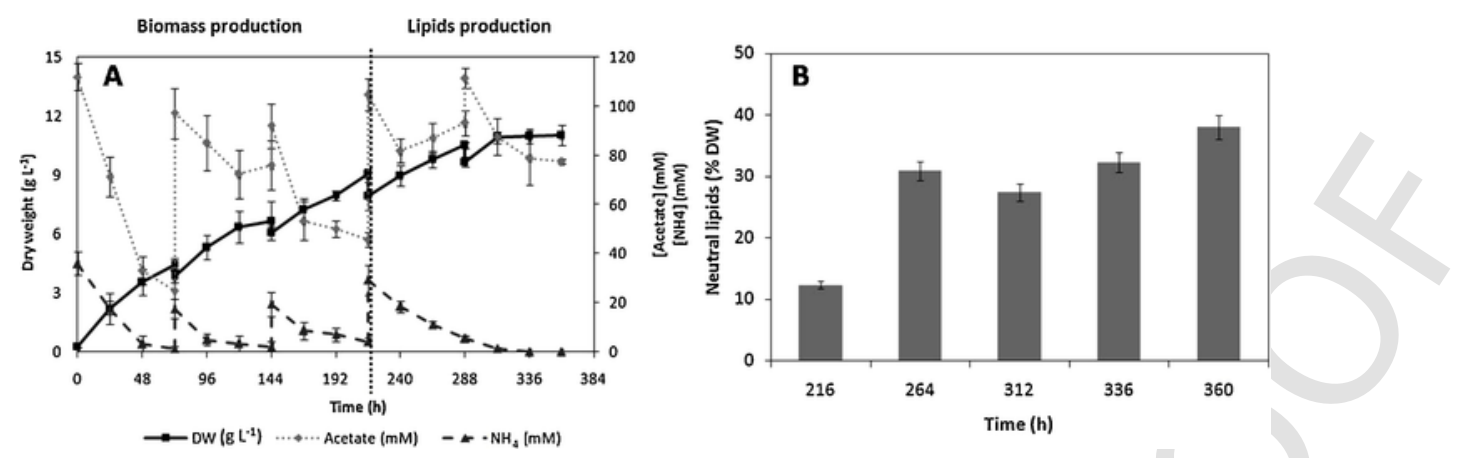

Fig. 7. Dry weight evolution, acetate and ammonium consumption of C. sorokinana cultivated in 2 L-STR reactor (A) and neutral lipid content (\% DW) determined at the indicated time. Culture was grown at $30^{\circ} \mathrm{C}, 550 \mathrm{rpm}$ and a light intensity of $100 \mu \mathrm{E} \mathrm{m}^{-2} \mathrm{~s}^{-1}$, in mixotrophic medium with the optimal concentration of acetate and ammonium. Periodical additions of wine waste lees and ammonium $(72,144$ and $216 \mathrm{~h})$ or only wine waste lees $(288 \mathrm{~h})$ were made at indicated times to recover the initial concentrations of ammonium and/ or acetate.

of 106:16:1 is optimal for microalgae, the air-dissolved $\mathrm{CO}_{2}$ and that generated during the respiration contribute to increase the $\mathrm{C}$ supply to optimal values in the mixotrophic culture, increasing the biomass production and consequently the productivity of the system.

Nitrogen deprivation in the second period of the experiment induced the accumulation of lipids and the decelerated growth (Fig. 7B, Table 3). The lipid content was determined at $216 \mathrm{~h}$, at which point the last addition of nitrogen source was made. It was repeatedly registered at regular intervals from the end of the $4^{\text {th }}$ batch cycle, when the nitrogen source was almost exhausted. The content of neutral lipids increased continuously during the last phase of the experiment, reaching a concentration of $38 \%\left(\mathrm{w} / \mathrm{w}\right.$; Fig. 7B) at the end of the $5^{\text {th }}$ batch. The lipid productivity obtained in this study $\left(193.37 \mathrm{mg} \mathrm{L}^{-1}\right.$ day $^{-1}$; Table 4) was higher than that in previous studies with $C$. sorokiniana grown with glucose or sodium acetate $[18,49]$ or with other microalgal species in mixotrophic conditions [50].

The accumulation of neutral lipids in fed-batch systems with sodium acetate or glucose as carbon source has been recently described in C. sorokiniana [51] and other microalgal species in mixotrophic conditions [52]. In agreement with the present results with wine wastes lees, these authors describe higher production of lipids in mixotrophic conditions and corroborate that the higher availability of acetate results in an elevated flux towards lipid biosynthesis as it integrates into the central metabolism as acetyl Co-A [53], the key precursor for lipid biosynthesis in microalgae. Attempts to culture C. sorokiniana with industrial water [26] or other industrial wastes [54] have had different degrees of success and have provided biomass and lipid productivities lower than those obtained with oxidized wine waste lees here.

\section{Conclusions}

It has been demonstrated, using reactors of different radius, that the influence of effective light is less pronounced when $C$. sorokiniana is cultured under mixotrophic conditions. However, to guarantee the economic feasibility of mixotrophic cultures it is necessary to find

Table 4

Kinetics parameters of $C$. sorokiniana growth in 2 L-STR fed-batch culture.

\begin{tabular}{clllll}
\hline$\left(\mathrm{h}^{-1}\right)$ & $\begin{array}{l}\mathrm{X}_{\max }(\mathrm{g} \\
\left.\mathrm{L}^{-1}\right)\end{array}$ & $\begin{array}{l}\operatorname{Prod}_{\mathrm{X}}(\mathrm{g} \\
\left.\mathrm{L}^{-1} \text { day }^{-1}\right)\end{array}$ & $\begin{array}{l}\mathrm{L}_{\mathrm{N}}(\mathrm{g} \\
\left.\mathrm{L}^{-1}\right)\end{array}$ & $\begin{array}{l}\mathrm{Y}_{\mathrm{L} / \mathrm{X}}(\mathrm{g} \\
\left.\mathrm{g}^{-1}\right)\end{array}$ & $\begin{array}{l}\operatorname{Prod}_{\mathrm{L}}(\mathrm{mg} \\
\left.\mathrm{L}^{-1} \text { day }^{-1}\right)\end{array}$ \\
\hline $0.039 \pm 0.008$ & 11.00 & 1.39 & 1.16 & 0.38 & 193.37 \\
\hline
\end{tabular}

- Specific Growth rate, calculated with DMFIT software; $X_{\max }$ - Maximum Biomass; $\operatorname{Prod}_{X}$ - Biomass Productivity; $L_{N}$ Neutral Lipids; $Y_{L / X}$ - Lipid Content; $\operatorname{Prod}_{L}$ - Lipids productivity an appropriate economical carbon source. Oxidized wine waste lees were chosen, among other agro-industrial wastes, as the best carbon source for C. sorokiniana. The fed-batch strategy and the medium optimization, with nutrient supplementation, have been found to be very effective in enhancing biomass and neutral lipid productivity, suggesting that this is a promising strategy for production of microalgal biomass.

\section{Uncited References}

\section{Acknowledgements}

Part of this work has been supported by research grants from the Spanish (AGL2016-74866-C32R-AEI/FEDER) and European governments (INTERREG VA-POCTEP- 2014-2020; 0055_ALGARED_PLUS_5_E) and the Portuguese Science Foundation (FCT) through the grant UID/MAR/00350/2013 to the CIMA of the University of Algarve. We thank Dr. Molinari from the University of Milan, for kindly providing the Acetobacter acetii strain. The help of CEIMAR University Excellence Campus is also acknowledged.

\section{References}

[1] I. Hamed, The evolution and versatility of microalgal biotechnology: A review, Compr Rev Food Sci Food Saf 15 (6) (2016) 1104-1123.

[2] RH Wijffels, M. Barbosa, An outlook on microalgal biofuels, Science 329 (5993) (2010) 796-799.

[3] JC Varela, H Pereira, M Vila, R. León, Production of carotenoids by microalgae: achievements and challenges, Photosynth Res 125 (3) (2015) 423-436.

[4] O Perez-Garcia, Escalante FME, de-Bashan LE, Bashan Y. Heterotrophic cultures of microalgae: Metabolism and potential products, Water Res 45 (1) (2011) $11-36$.

[5] D Martins, L Custódio, L Barreira, H Pereira, R Ben-Hamadou, et al., Alternative sources of n-3 long-chain polyunsaturated fatty acids in marine microalgae, Mar Drugs 11 (7) (2013) 2259-2281.

[6] G Senhorinho, G Ross, J. Scott, Cyanobacteria and eukaryotic microalgae as potential sources of antibiotics, Phycologia 54 (3) (2015) 271-282.

[7] X Luo, P Su, W. Zhang, Advances in microalgae-derived phytosterols for functional food and pharmaceutical applications, Mar Drugs 13 (7) (2015) 4231-4254.

[8] Y. Chisti, Biodiesel from microalgae, Biotechnol Adv 25 (3) (2007) 294-306.

[9] A Raheem, WAKG Wan Azlina, YH Taufiq Yap, MK Danquah, R. Harun, Thermochemical conversion of microalgal biomass for biofuel production, Renew Sust Energ Rev 49 (2015) 990-999.

[10] KWM Tan, YK. Lee, The dilemma for lipid productivity in green microalgae: importance of substrate provision in improving oil yield without sacrificing growth, Biotechnol Biofuels 9 (1) (2016).

[11] Y. Chisti, Encyclopedia of bioprocess technology: fermentation, biocatalysis, and bioseparation, 5, Wiley, 19992379-2406. 
[12] FG Acién, JM Fernández, JJ Magán, E. Molina, Production cost of a real microalgae production plant and strategies to reduce it, Biotechnol Adv 30 (6) (2012) 1344-1353.

[13] Y. Chisti, Constraints to commercialization of algal fuels, J Biotechnol 167 (3) (2013) 201-214.

[14] L Wobbe, C. Remacle, Improving the sunlight-to-biomass conversion efficiency in microalgal biofactories, J Biotechnol 201 (2015) 28-42.

[15] B Zhao, Y. Su, Process effect of microalgal-carbon dioxide fixation and biomass production: A review, Renew Sust Energ Rev 31 (2014) 121-132.

[16] J Wang, H Yang, F. Wang, Mixotrophic cultivation of microalgae for biodiesel production: Status and prospects, Appl Biochem Biotechnol 172 (7) (2014) 3307-3329.

[17] T Li, Y Zheng, L Yu, S. Chen, High productivity cultivation of a heat-resistant microalga Chlorella sorokiniana for biofuel production, Bioresource Technol 131 (2013) 60-67.

[18] V Kumar, M Muthuraj, B Palabhanvi, AK Ghoshal, D. Das, High cell density lipid rich cultivation of a novel microalgal isolate Chlorella sorokiniana FC6 IITG in a single-stage fed-batch mode under mixotrophic condition, Bioresource Technol 170 (2014) 115-124.

[19] K-L Yeh, C-Y Chen, J-S. Chang, pH-stat photoheterotrophic cultivation of indigenous Chlorella vulgaris ESP-31 for biomass and lipid production using acetic acid as the carbon source, Biochem Eng J 64 (2012) 1-7.

[20] K Paranjape, GB Leite, PC. Hallenbeck, Effect of nitrogen regime on microalgal lipid production during mixotrophic growth with glycerol, Bioresource Technol 214 (2016) 778-786.

[21] B Ravindran, S Gupta, W-M Cho, J Kim, S Lee, et al., Microalgae potential and multiple roles-current progress and future prospects - An overview, Sustainability 8 (12) (2016) 1215.

[22] B Rodrigues, C Quintas, A Constantino, S Raposo, JM Peinado, ME. Lima-Costa, Kinetic and energetic parameters of carob wastes fermentation by Saccharomyces cerevisiae: Crabtree effect, ethanol toxicity, and invertase repression, J Microbiol Biotechnol 25 (6) (2015) 837-844.

[23] S Raposo, A Constantino, F Rodrigues, B Rodrigues, ME. Lima-Costa, Nitrogen sources screening for ethanol production using carob industrial wastes, Appl Biochem Biotechnol 181 (2) (2017) 827-843.

[24] $\mathrm{H} \mathrm{Xu}, \mathrm{X}$ Miao, Q. Wu, High quality biodiesel production from a microalga Chlorella protothecoides by heterotrophic growth in fermenters, J Biotechnol 126 (4) (2006) 499-507.

[25] B Rodrigues, ME Lima-Costa, A Constantino, S Raposo, C Felizardo, et al., Growth kinetics and physiological behavior of co-cultures of Saccharomyces cerevisiae and Kluyveromyces lactis, fermenting carob sugars extracted with whey, Enzyme Microb Tech 92 (2016) 41-48.

[26] AM Lizzul, P Hellier, S Purton, F Baganz, N Ladommatos, L. Campos, Combined remediation and lipid production using Chlorella sorokiniana grown on wastewater and exhaust gases, Bioresource Technol 151 (2014) 12-18.

[27] M Giovanardi, L Ferroni, C Baldisserotto, P Tedeschi, A Maietti, et al., Morphophysiological analyses of Neochloris oleoabundans (Chlorophyta) grown mixotrophically in a carbon-rich waste product, Protoplasma 250 (1) (2012) $161-174$.

[28] S Abad, X. Turon, Valorization of biodiesel derived glycerol as a carbon source to obtain added-value metabolites: Focus on polyunsaturated fatty acids, Biotechnol Adv 30 (3) (2012) 733-741.

[29] M Cuaresma, M Janssen, C Vílchez, RH. Wijffels, Productivity of Chlorella sorokiniana in a short light-path (SLP) panel photobioreactor under high irradiance, Biotechnol Bioeng 104 (2) (2009) 352-359.

[30] N. Sueoka, Mitotic replication of deoxyribonucleic acid in Chlamydomonas reinhardtii, Proc Natl Acad Sci USA 46 (1) (1960) 83-91.

[31] ME Lima-Costa, C Tavares, S Raposo, B Rodrigues, JM. Peinado, Kinetics of sugars consumption and ethanol inhibition in carob pulp fermentation by Saccharomyces cerevisiae in batch and fed-batch cultures, J Ind Microbiol Biotechnol 39 (5) (2012) 789-797.

[32] K Kimura, M Yamaoka, Y. Kamisaka, Rapid estimation of lipids in oleaginous fungi and yeasts using Nile red fluorescence, J Microbiol Methods 56 (3) (2004) 331-338.

[33] W Chen, C Zhang, L Song, M Sommerfeld, Q. Hu, A high throughput Nile red method for quantitative measurement of neutral lipids in microalgae, J Microbiol Methods 77 (1) (2009) 41-47.

[34] E Bertozzini, L Galluzzi, A Penna, M. Magnani, Application of the standard addition method for the absolute quantification of neutral lipids in microalgae using Nile red, J Microbiol Methods 87 (1) (2011) 17-23.
[35] F Acién-Fernández, F Gracía-Camacho, J Sánchez-Pérez, J Fernández-Sevilla, E. Molina-Grima, A model for light distribution and average solar irradiance inside outdoor tubular photobioreactors for the microalgal mass culture, Biotechnol Bioeng 55 (5) (1997) 701-714.

[36] R León, F. Galván, Analysis of effective light in different photobioreactors: its influence on growth, photosynthetic activity and glycerol production by the freshwater green alga Chlamydomonas reinhardtii, World J Microbiol Biotechnol 13 (1999) 237-239.

[37] E Molina-Grima, F Acién-Fernández, F Gracía-Camacho, Y. Chisti, Photobioreactors: light regime, mass transfer, and scale-up, J Biotechnol 70 (1999) 231-247.

[38] VO Adesanya, MP Davey, SA Scott, AG. Smith, Kinetic modelling of growth and storage molecule production in microalgae under mixotrophic and autotrophic conditions, Bioresource Technol 157 (2014) 293-304.

[39] EJ Lohman, RD Gardner, T Pedersen, BM Peyton, KE Cooksey, R. Gerlach, Optimized inorganic carbon regime for enhanced growth and lipid accumulation in Chlorella vulgaris, Biotechnol Biofuels 8 (1) (2015).

[40] B Gris, T Morosinotto, GM Giacometti, A Bertucco, E. Sforza, Cultivation of Scenedesmus obliquus in photobioreactors: Effects of light intensities and light-dark cycles on growth, productivity, and biochemical composition, Appl Biochem Biotechnol 172 (5) (2013) 2377-2389.

[41] AP Abreu, B Fernandes, AA Vicente, J Teixeira, G. Dragone, Mixotrophic cultivation of Chlorella vulgaris using industrial dairy waste as organic carbon source, Bioresource Technol 118 (2012) 61-66

[42] Y Wang, H Rischer, NT Eriksen, MG. Wiebe, Mixotrophic continuous flow cultivation of Chlorella protothecoides for lipids, Bioresource Technol 144 (2013) 608-614.

[43] S Kim, JE Park, YB Cho, SJ. Hwang, Growth rate, organic carbon and nutrient removal rates of Chlorella sorokiniana in autotrophic, heterotrophic and mixotrophic conditions, Bioresource Technol 144 (2013) 8-13.

[44] Y Wang, S-Y Chiu, S-H Ho, Z Liu, T Hasunuma, et al., Improving carbohydrate production of Chlorella sorokiniana NIES-2168 through semi-continuous process coupled with mixotrophic cultivation, Biotechnol J 11 (8) (2016) 1072-1081.

[45] G Markou, O Depraetere, K. Muylaert, Effect of ammonia on the photosynthetic activity of Arthrospira and Chlorella: A study on chlorophyll fluorescence and electron transport, Algal Res 16 (2016) 449-457.

[46] T Cakmak, P Angun, YE Demiray, AD Ozkan, Z Elibol, T. Tekinay, Differential effects of nitrogen and sulfur deprivation on growth and biodiesel feedstock production of Chlamydomonas reinhardtii, Biotechnol Bioeng 109 (2012) 1947-1957.

[47] T Li, Y Zheng, L Yu, S. Chen, Mixotrophic cultivation of a Chlorella sorokiniana strain for enhanced biomass and lipid production, Biomass Bioenerg 66 (2014) 204-213.

[48] H Hillebrand, U. Sommer, The nutrient stoichiometry of benthic microalgal growth: Redfield proportions are optimal, Limnol Oceanogr 44 (2) (1999) $440-446$.

[49] S Zheng, M He, Y Sui, T Gebreluel, S Zou, et al., Kelp waste extracts combined with acetate enhances the biofuel characteristics of Chlorella sorokiniana, Bioresource Technol 225 (2017) 142-150.

[50] W Lin, P Li, Z Liao, J. Luo, Detoxification of ammonium to Nannochloropsis oculata and enhancement of lipid production by mixotrophic growth with acetate, Bioresource Technol 227 (2017) 404-407.

[51] V Kumar, M Muthuraj, B Palabhanvi, D. Das, Synchronized growth and neutral lipid accumulation in Chlorella sorokiniana FC6 IITG under continuous mode of operation, Bioresource Technol 200 (2016) 770-779.

[52] YZ Wang, PC Hallenbeck, GB Leite, K Paranjape, DQ. Huo, Growth and lipid accumulation of indigenous algal strains under photoautotrophic and mixotrophic modes at low temperatures, Algal Res 16 (2016) 195-200.

[53] M Muthuraj, B Palabhanvi, S Misra, V Kumar, K Sivalingavasu, D. Das, Flux balance analysis of Chlorella sp. FC2 IITG under photoautotrophic and heterotrophic growth conditions, Photosynth Res 118 (1-2) (2013) 167-179.

[54] B Riaño, S Blanco, E Becares, MC. García-González, Bioremediation and biomass harvesting of anaerobic digested cheese whey in microalgal-based systems for lipid production, Ecol Eng 97 (2016) 40-45. 